\title{
Airport Monopoly and Regulation: Practice and Reform in China
}

\author{
Jianwei Huang ${ }^{1, \text { a }}$ \\ ${ }^{1}$ Shanghai University of Engineering Science, Shanghai 201620, China. \\ ajianwei0221@126.com
}

Keywords: airport, regional natural monopoly, price cap regulation

\begin{abstract}
Airport industry is believed to be a regional natural monopoly. As a result, price regulation is used to deal with the monopoly of airports. By comparing the different measures of price regulation in developed countries and analyzing on the practice of the price regulation in China's airport in detail, this paper puts forward the idea of the price cap regulation for airports in China. Meanwhile, the preliminary scheme of the price cap regulation is designed to promote the reform of airport regulation in China.
\end{abstract}

\section{Introduction}

Airport industry is one of the most important sub industries of air transport industry. It is a natural monopoly, which is obviously different from the airline sub industry. This kind of natural monopoly is particularly prominent within certain distance from the airport. In this paper, it is called regional natural monopoly of airport [1]. The implementation of price regulation on airports is therefore the choice of most countries.

\section{Airport Monopoly and Regulation Measures in Different Countries}

The Characteristics of Airport Monopoly. Airport industry has an obvious characteristic of regional monopoly. Due to the restrictions of economies of transport network and economies of scale, airports need to be properly layout and keep an economic scale. This determines that there is usually only one monopoly airport in a certain region.

It has formed a sharp contrast between regional natural monopoly of airports and the competition of airlines. Usually, if there are more airports in one country, the airport industry should be more competitive. Similarly, if there are fewer airlines in one country, the monopoly should be stronger. It seems that data support such a judgment if the monopoly power can be reflected by the market concentration rate. The average concentration rates of the first $n$ enterprises (CRn) can be calculated (See Table 1) . During the period of 2002-2010, CR8 of China's airline industry was $76.7 \%$, while CR8 of airport industry was $53.2 \%$ in the same period. That is, the market concentration (CR8) of the airport industry is far below the airline industry, so does CR4.

Quite the opposite in fact, airport industry has shown a greater monopoly power than the airline industry. How to explain the contradiction between the concentration rate and the actual performance of the market? Although there are fewer airlines than airports in China, airlines maintained a multi-market contact each other which led to more competition [2]. In contrast, even if there are more airports in China, they are located in different regions and keep little contact or competition in their own region. Thus, regional natural monopoly is formed in the region of each airport. 
Table 1 Market concentration of China's airport industry and airline industry

\begin{tabular}{ccccc}
\hline \multirow{2}{*}{ Year } & \multicolumn{2}{c}{ Airline industry } & \multicolumn{2}{c}{ Airport industry } \\
& CR4(\%) & CR8(\%) & CR4(\%) & CR8(\%) \\
\hline 2002 & 57.8 & 72.4 & 39.61 & 56.88 \\
2003 & 63.1 & 77.5 & 37.40 & 55.39 \\
2004 & 61.7 & 76.8 & 37.66 & 55.53 \\
2005 & 72.4 & 86.4 & 37.29 & 54.90 \\
2006 & 65.4 & 80.9 & 36.48 & 54.25 \\
2007 & 61.7 & 77.2 & 35.12 & 52.32 \\
2008 & 58.8 & 74.4 & 34.62 & 51.18 \\
2009 & 57.9 & 73.6 & 32.80 & 49.54 \\
2010 & 55.6 & 71.3 & 33.10 & 49.18 \\
Average & 61.6 & 76.7 & 36.0 & 53.2 \\
\hline
\end{tabular}

Source: National Airport Production Statistics Bulletin, 2002-2010[3];

Statistical Data on Civil Aviation of China, 2003-2011[4].

Comparison of Regulation Measures of Different Countries. Since the airport industry is a regional natural monopoly, Regulatory agencies should carry out regulations according to the theory of regulation economics.This paper focuses on the issue of airport price regulation. For convenience, regulation measures in some developed countries are listed as shown in Table 2.

Table 2 Regulation measures in different countries

\begin{tabular}{cccc}
\hline Numble & Country & Applicableairport & Regulation measure \\
\hline 1 & the United Kingdom & $\begin{array}{c}\text { large airports } \\
\text { small airports } \\
\text { Hamburg Airport }\end{array}$ & $\begin{array}{c}\text { 5-year period of price cap regulation } \\
\text { no regulations }\end{array}$ \\
2 & Germany & $\begin{array}{c}\text { Frankfurt airport } \\
\text { from cost plus regulation to price cap regulation } \\
\text { price regulation of "risk sharing" }\end{array}$ \\
3 & Australia & all airports & from price cap regulation to price monitoring \\
4 & New Zealand & all airports & "trigger regulation" \\
5 & the United States & most airports & cost-based pricing \\
6 & Canada & main airports & peak hour auction \\
\hline
\end{tabular}

Some important points can be summed up from the practice of the regulation of these airports: Firstly, price regulation is a commonly used measure for governments to deal with the monopoly of airport; Secondly, cost-based regulation encountered many difficulties so that the price cap regulation became the choice of most countries; Thirdly, deregulation of airport has been adopted by some countries. They preferred to take price monitoring or "trigger regulation", that is, as long as the airport price behavior is desirable, it is not regulated, otherwise it will be reregulated.

\section{Practice of Price Regulation in China's Airport}

Due to the regional natural monopoly of the airport, price regulation has been carried out in China for a long time. What's more, the reform of regulation has also been carried out for several times.

Key Points of Regulation of Airport Industry in China. The current price regulation scheme of airport industry in China can be summarized as follows [5]:

Airport charges are collected on the basis of the classification of airports. According to the traffic flow, airports in China are divided into three categories. Hub airports charge less than medium and small ones.

The items of airport charges are unified. Airport charges are consisted of aviation business charges, non-aviation key business charges and non-aviation other business charges. Among them, aviation businesses charges are composed of takeoff and landing fees, parking fees, passenger and bridge fees, passenger service fees and security charges. Non-aviation key business charges cover first-class cabin and business class lounge rental fees. All fees and charges are given in detail.

The management mode of airport charges is reformed. The above fees and charges are subject to 
government guidance. The benchmark price is approved by Civil Aviation Administration of China and National Development and Reform Commission of China according to the reasonable cost of facilities \& services provided by airport authority and user's acceptance capacity and so on. The benchmark price is generally not upward floating, and allowed to float downward to some degree. Airport authority and other service provider need to negotiate with users to make joint decision about the degree of floating downward according to their facilities and service level.

Discussions on the Present Regulation Scheme. It can be discussed from two aspects of positive and negative.

The advantages of the present scheme may include:

Firstly, the present scheme is subject to government guidance rather than government pricing. It allows the price to fluctuate in a certain range, which provides airports a certain scope of independent pricing. At the same time, airport monopoly power is restricted to achieve the purpose of regulation.

Secondly, it meets the majority of the five principles of ICAO airport pricing: It requires the benchmark price to be determined by the reasonable cost of airport facilities \& services and user's acceptance capacity, which meets the cost related principle; It allows airport authority and other service provider to negotiate with users to make joint decision about the price, which meets the principle of consultation; The cost of aviation and non-aviation business is not accounted separately, which meets the principle of single-till; It has eliminated the difference of aviation business charges between domestic and foreign airlines in 2013, which meets the principle of non discrimination.

The disadvantages of the present scheme may include:

Firstly, the cost related principle of the present scheme is not clearly defined in accordance with the average cost (zero revenue) or cost based rate-of-return regulation. However, from a realistic point of view of the reform of airports, there should be a certain rate of return. It is not clear how much the rate is, which may lead to conflicts of interest between airlines and airports in the future. Even though the type of cost based regulation is cleared, it may lead to undesirable airport investments (Averch-Johnson effect). The new scheme is also not clear about the conditions and period to check the average cost of the airports.

Secondly, the present scheme provides a benchmark price of aviation and non-aviation business and allows the price to float downward but not upward. However it still should not be considered a price cap regulation. Price cap regulation should be separated from the cost factors otherwise it will inevitably become a cost based regulation.

Thirdly, the present scheme is still lack of incentives. It should be able to encourage the airport to reduce costs, improve productivity and maximize the efficiency of facilities and employees. Meanwhile, it should benefit both airports and airlines from the growth of air transport.

Fourthly, it has always been lack of truly independent regulatory agencies in China's air transport industry.

\section{Design Price Cap Regulation for Aviation Business in China's Airport Industry}

Reasons for Price Cap Regulation. According to the problems of the airport price regulation in China, it is obvious that the present scheme needs to be improved and perfected. For airport non-aviation business, franchise is very popular in the world, so there will be no further discussions in this paper. For aviation business, this paper believes that price cap regulation should be carried out.

Price cap regulation can encourage the airport to reduce costs and improve productivity. Airports are more motivated to exaggerate their true cost in cost plus regulation, because the expansion of the cost base means that the total profits will increase. Sometimes airports may be more willing to increase investment in excess of the actual needs in order to expand the cost of capital, which may lead to a significant A-J effect.

Basic requirements have been reached for price cap regulation to be carried out in airport industry in China. Price cap regulation is a relatively mature type of incentive regulation. It has or had been practiced by airports in Britain, Germany, Australia and many other countries. It has also 
been successfully applied in other monopoly industries such as electric power and telecommunications. Price cap regulation encourages airports to reduce costs in order to get more profits.

Moreover, small and medium airports are usually willing to give airlines and passengers a certain price discount in order to increase the utilization of its facilities to reach the scale of economies. Therefore, when the price cap regulation is carried out, airports will use their private cost information to determine the price discount, which will benefit both airlines and passengers.

The present price regulation scheme has laid a preliminary foundation for the implementation of price cap regulation. It has met the basic requirements of price cap regulation through provisions which allow the price to float downward but not upward.

The mode of Price Cap Regulation for Aviation Business. The pricing model of price cap regulation is not very complicated, and the basic model is as follows:

$P_{t}=P_{t-1}[1+(R P I-X)]$

Where, $P_{t}$ is the price in regulation for period $t$ decided by the regulator; $P_{t-1}$ is the price in regulation for the previous period $t-1 ; R P I$ is the retail price index; $X$ is the growth rate of productivity predetermined for current regulation period by the regulator. When $R P I-X<0$, price must be reduced.

What's most important here is the determination of $X$. Passenger throughput growth rate is usually used in place of an increase in airport productivity. In China, passenger business and cargo business are usually developed in parallel by airport authority, so cargo throughput can be incorporated into passenger throughput. In addition, flight movements that reflect how busy the airports are should also be included in $X$. Thus the average value of the growth rate of these three indicators can be regarded as an overall growth rate of $X$. In the past ten years, China has been in a period of rapid development in air transport, which will excessively magnify the value of $X$. As a result, there may be an unreasonable big increase in airport revenue. So sliding scale model may be adopted [6]. That is, given the overall growth rate $X=a \%$, which is predetermined for current regulation period, if the real overall growth rate $X^{\prime}$ is bigger than $a \%$, let $X$ add $0.5 \%$ when $X^{\prime}$ increase by every $1 \%$ and vice versa. This allows airlines and airports to share the benefits and risks.

In this way, the new pricing model will be:

$$
P_{t}=P_{t-1}[1+(R P I-X)-s C S]
$$

Where, scs is the coefficient of the sliding scale model.

In practice, $X$ should be decided by negotiation between parties. Due to the difference of growth rate between various types of airports, classification of airport is suggested, and $X$ will be set in accordance with the type of airport.

Another important issue is the determination of RPI. Monopoly industries, such as the telecommunications industry, usually face a number of individual consumers in price cap regulation, so it is appropriate to use RPI to reflect the price level. However the main customer of the airport aviation business is the airlines. This means that the changes in RPI do not necessarily coincide with price changes of airport input factors. In this way, the price cap adjusted by $R P I$ will not reflect the impact of factor price changes on airport service prices. RPI should be replaced by PPI (producer price index), and the pricing model will be:

$$
P_{t}=P_{t-1}[1+(P P I-X)-s C S]
$$

\section{Summary}

Airport industry is a regional natural monopoly so that price regulations are widely adopted by the regulatory authorities around the world. In China, price regulations have been carried out for a long time, but most of these regulations are based on cost and lack of necessary incentives. Price cap regulation has been successfully used in airport regulation by developed countries, therefore it can be used as a kind of beneficial attempt of the airport price regulation reform in China. 


\section{Acknowledgements}

This paper has been supported by the Shanghai Municipal Education Committee (Project No. s201508001). Thanks to Dr. Yao Hongguang who gave me many valuable suggestions.

\section{References}

[1] H.-M. Niemeier, Capacity utilization, investment and regulatory reform of German airports, in P. Forsyth etc.(Eds.), The Economic Regulation of Airports: Recent Developments in Australasia, North America and Europe, China Civil Aviation Publishing House, Beijing, 2009, pp. 210-243.

[2] A. Karnani, B. Wernerfelt, Multiple point competition, Strategic Management Journal. 6(1985) 87-96.

[3] National Airport Production Statistics Bulletin 2002-2010, http://www.caac.gov.cn/XXGK/XX GK/index_172.html?fl=11.

[4] Development \& Planning Department of CAAC, Statistical Data on Civil Aviation of China, China Civil Aviation Publishing House, Beijing, 2003-2011.

[5] The reform scheme of charges in the civil aviation airports. http://www.caac.gov.cn/ XXGK/XXGK/index_172.html?fl=10 (12.28.2007.)

[6] T. Immelmann, Regulation in times of crisis: experiences with a public-private price cap contract at Hamburg Airport, in P. Forsyth etc. (Eds.), The Economic Regulation of Airports: Recent Developments in Australasia, North America and Europe, China Civil Aviation Publishing House, Beijing, 2009, pp. 201-209. 